\title{
Mechanical Behavior of Nano-Scaled Graphene Oxide Reinforced High-Density Polymer Ethylene for Orthopedic Implants
}

\author{
Nadeem Faisal ${ }^{1 *}$ (iD) \\ 1 Assistant Professor, Department of Mechanical Engineering, ITM University, Gwalior, India \\ * Correspondence: ndmfaisal@gmail.com;
}

Scopus Author ID 57201153331

Received: 8.05.2020; Revised: 3.06.2020; Accepted: 4.06.2020; Published: 7.06.2020

\begin{abstract}
The application of bio-composite materials is in trends recently, for both commercials as well as the scientific community. In order to achieve inherent strength and efficient performance, biocompatible materials are often modified. This is done with an aim to replace organic cells/tissues if required. In recent times, the polymer composites are used as an alternative for body implants than traditional metal-based components. Cost inefficiency and corrosion resistivity are the major problems associated with metallic implants. Polymer composite offers similar advantages as that of metallic based components. Moreover, it can also be molded in the requisite shape, are cost-efficient, have a high corrosion rate, and less weight. This paper aims to fabricate a biopolymer nanocomposite with efficient fatigue, mechanical, and wear properties, which is suitable for human implant applications. The studies evident effective mechanical and efficient tribological properties, demonstrated by implants for knee and hip replacement. The graphene oxide employed in the experiment study retains antibiotic properties and is also tends to be bio-compatible. Nano graphene oxide, along with high-density polyethylene at varying wt.\% of $0.5-2.5 \%$, was reinforced, which resulted in better tribological outcomes. This composite material is environment friendly and has the potential to be used for numerous applications.
\end{abstract}

Keywords: nano-graphene oxide; high-density polymer ethylene; mechanical behavior; fatigue testing; wear testing.

(C) 2020 by the authors. This article is an open-access article distributed under the terms and conditions of the Creative Commons Attribution (CC BY) license (https://creativecommons.org/licenses/by/4.0/).

\section{Introduction}

The HDPE (high-density polyethylene) has a wide array of applications in various fields, including biomedical, daily household items, and defense as these fields require highperformance materials, and the HDPE tends to be cost-effective, corrosion resistance, durable and tough [1-4]. Apart from the benefits, certain disadvantages like its abrasion resistance and creep decrease the efficiency of polymer material [5-7]. Amidst this rundown, Ramanathan et al., in their paper, proposed the use of nanofillers in order to improve the mechanical properties for polymer-based materials [8]. Several researchers have concluded that the addition of nanoparticles as reinforcements can enhance the various properties of materials, which they initially lack [9-13]. There has also been a tremendous amount of increment in the use of nanoparticles for numerous biomedical applications in recent years [14-21].

Despite this, the ideal material for using as fillers in polymers has always been a matter of debate in the research world. Owing to its tensile strength, CNT (carbon nanotube) as 
reinforcement has been considered an ideal candidate by researchers; however, due to numerous aspects, CNT's are still in the development phase [22-24]. The complex structure of CNT's obstructs the matrix to reinforcement load transfer, as it fails to hold on to the surface of the polymer matrix [25]. Other than this, the dispersion of CNT in a viscous solution is also a significant challenge, limiting the scope of polymer applications. The fabrication of CNT's resolves this issue. However, at the same time, it also disturbs their confinement structure, which leads to a declining trend in the tensile strength of the polymer [26-28]. Amidst this scenario, the functionalized graphene as an alternative replacement material is adequate [29]. The graphene retains similar properties as of CNT's [30]. By its flat structure, at matrix, the strength transformation by diverse direction is viable and it also successfully reduces the matrix slippage trouble. This is an advantage, as the tensile strength of CNT is robust along the length only [31-32]. Several research studies reported an increase in mechanical properties of graphene-based polymers, integrated with nanocomposites [33-37].

Yoon et al., in their article, discuss the improvement of mechanical \& thermomechanical properties of a PLGA nanofiber mesh, reinforced with graphene oxide. Only 1-2 wt.\% of graphene oxide was integrated into the polymer [38]. A different study demonstrated enhanced flexural strength of the HDPE based nanocomposites, upon the integration of paraffin wax along with graphene; in comparison to the uncoated polymer surface [39, 40]. Interaction between graphene and polymer matrix, along with adequate dispersion and orientation of the graphene with polymer matrix, is still an obstacle, as it hinders the load transformation from the matrix to reinforcement. Due to multilayer graphene slippage and inadequate interphase between graphene and polymer matrix, understanding of strength for graphene-based applications is still not adequately understood [41-43].

This paper focuses upon the determination of optimum composition and methodology for the fabrication of a biopolymer nanocomposite along with efficient fatigue, mechanical \& wear properties. The fracture trend of the composite is also discussed. The focal aim of the entire study was to fabricate a clinically relevant polymer material, which can be used for the fabrication of orthopedic implants.

\section{Materials and Methods}

\subsection{HDPE composites processing.}

Specimens were fabricated at a temperature range from $120^{\circ} \mathrm{C}-160^{\circ} \mathrm{C}$, the polyethylene high-density composite samples were obtained. Unlike nano polymers; the combination of resin reinforcement for HDPE is not obtained directly. After the complete homogenous blend of the solvent, the nanopowder from the solvent matrix tends to be redistributed in the polymer matrix, followed by the evaporation; this is achieved by distributing the nanoparticles of optimum dimensions in the solvent through appropriate technique. The HDPE pellets used for this study were in the form of pellets, and graphene oxide nanoparticles obtained for the study were in the form of long flakes. Both these materials were obtained from Sigma Aldrich, Hyderabad, India. The properties of both these materials HDPE and nano-graphene oxide are shown in Table 1 below. 
Table 1. Properties of high-density polyethylene and nano-graphene oxide (as said by the supplier)

\begin{tabular}{l|c|c|c|c}
\multicolumn{1}{c|}{ Material } & $\begin{array}{c}\text { Yield Strenght } \\
\text { (MPa) }\end{array}$ & $\begin{array}{c}\text { Ultimate Tensile } \\
\text { Strenght (MPa) }\end{array}$ & Elongation (\%) & Young's Modulus \\
\hline $\begin{array}{l}\text { High-desnity } \\
\text { polyethylene }\end{array}$ & 7.005 & 34.74 & 48 & 547.48 \\
\hline $\begin{array}{l}\text { Nano graphene } \\
\text { oxide }\end{array}$ & 34.378 & 130 & 0.6 & 2400
\end{tabular}

\subsection{Ultrasonic vibrations.}

The inspiration for using ultrasonic vibrations was obtained through studying various experimentations performed by other researchers to increase the particle size, surface area, and proper mixture of the nanoparticles in the composites [44-48].

The steps refereed are in respect to the specimen containing $0.5 \%$ nano composition, along with $50 \mathrm{ml}$ xylene as a solvent and $0.5 \mathrm{~g}$ of nano-graphene oxide particles as solute. The specimen was precisely weighed via a weighing balance, followed by the placement of the specimen in an ultrasonic vibrator, partially submerged into water. Relatively, $20000 \mathrm{~Hz}$ of ultrasonic vibration frequency was produced for a time of 30 minutes, in order to obtain nano dimensions of the graphene oxide via vigorous agitation. Ideally, nanoparticles were supposed to obtain the dimensions of around 60-70(nm) x 60-70(nm) x 4-5(nm), given they are precisely distributed. The electron microscopy scanning technique was used for determining the definite dimensions of the nanoparticles. The obtained nano-solvent mixture would be used as the reinforcement component.

\subsection{Melt blending.}

Many researchers in recent years have used the melt blending process for an efficient blending of different materials and enhancement in properties of the materials [49-54]. For the melt blending process, $100 \mathrm{~g}$ of HDPE was placed in a stainless steel container followed by a heat treatment via a hot plate eater. Promptly upon the indication of heat input being turned on, xylene was added. The maintained matrix-polymer volume ratio was 5:1. Thus $500 \mathrm{ml}$ of xylene w.r.t pellets were added in the stainless-steel container. The solvent, xylene, tends to dissolve the HDPE pellets rapidly due to the heat treatment provided earlier. At $140^{\circ} \mathrm{C}$, the HDPE pellets started melting. Minutes before this point, the nano powder-xylene mixture was integrated. The vaporizing temperature for xylene and the melting point of HDPE pellets are similar. As the melting process of pellets started, the compatibility of nano-graphene oxide for polymer increased, and the vaporization phase of xylene provided ideal transformation rate and distribution of nanoparticles upon the polymer matrix. During this process, a temperature range of $150-180^{\circ} \mathrm{C}$ was maintained, as the vaporization phase for xylene occurs at this range only. Within a few minutes HDPE, along with ideally distributed nano-graphene oxide, was obtained, as the xylene used was effectively vaporized in the atmosphere.

\subsection{Vacuum molding.}

The composite is obtained in a semi-fluid state; initially, the composite was manually moved into a compression mold plate, followed by the squeezing process in order to obtain plate specimens. A field of blowholes around the center was detected for the obtained specimens. This obstruction was partially reduced by the preheating treatment. In order to completely eradicate this colony of blowholes, the quenching method was employed, for which 
the mold plates were tightly confiscated and immersed in water for several minutes and were then cooled for the next 24 hours. These treatments had a considerable effect on the blowhole area. However, it was observed that in the presence of atmospheric air, the blowhole tends to form. In order to eliminate this phenomenon, a vacuum treatment was contemplated. For this, an apparatus consisting of a vacuum pump, along with a vacuum box, was built. The composite at a vacuum pressure of 0.8 bar was transported from the stainless-steel container to the molding plates, which were tightly confiscated, before the vacuum sustentation for 5 minutes, followed by the cure treatment of the same time frame. After this procedure, the specimens were further quenched, which resulted in a defect less specimen along with a smooth surface finish.

The technique mentioned was employed for the manufacturing of other samples having $0.5 \%, 1 \%, 1.5 \%, 2 \%, \& 2.5 \%$ wt. $\%$ of nano-graphene oxide.

\section{Results and Discussion}

To verify the reliability of the proposed composite polymer, certain characteristics such as bonding stability, fatigue, strength, and wear resistance were evaluated. This inspection allowed the assessment of HDPE for clinically relevant applications. In order to detect the distribution of nanoparticles, micro-structural bonding, reinforcement dimensions, and its stability inside the matrix, scanning electron microscopy was employed. In order to determine the composite failure, several loads were periodically engaged, through which the results for fatigue tests were obtained. For a composite polymer to be clinically relevant, its wear properties are crucial. Fixed travel distances, load, and speed parameters were employed for testing the effect of incrementing nanoparticles composition on wear rate.

\subsection{Scanning Electron Microscopy.}

The SEM (scanning electron microscope) employs a concentrated electron beam to scan and obtain images of the sample provided, with a resolution greater than $1 \mathrm{~nm}$. These electrons interact with specimen atoms, which indicates the surface composition and its topography through information obtained via various signals. In order to obtain an image, the raster scan pattern is adopted via an electron beam. The position of an electron beam, along with a detected signal is used for an image generation. This technique is able to analyze the specimen in harsh environmental conditions, high-low vacuum, and even at cryogenic temperatures. SEM efficiently detects the secondary electrons emitted by the specimen's atoms because of the electron beam. However, the electron detection is influenced by the specimen's topography. By virtue of sample scanning, coupled with the detection of secondary electrons, an image of the specimen's surface topography is created. The scanning electron microscope (JEOL, Model JSM 6510LV, Japan) was used for the above experimentation is shown in Figure 1 below. Figure 2 depicts the HDPE microstructure distribution, along with nanopowder graphene oxide. The uniform dispersion of nanopowder and the HDPE is way significant, as it influences the fatigue strength of the composite material. In order to verify this, Figure. 2 is zoomed up to 3 levels. It is evident from the image that material is evenly distributed, with no sign of agglomerates, indicating the apprehension of desired properties and enhanced fatigue life. 


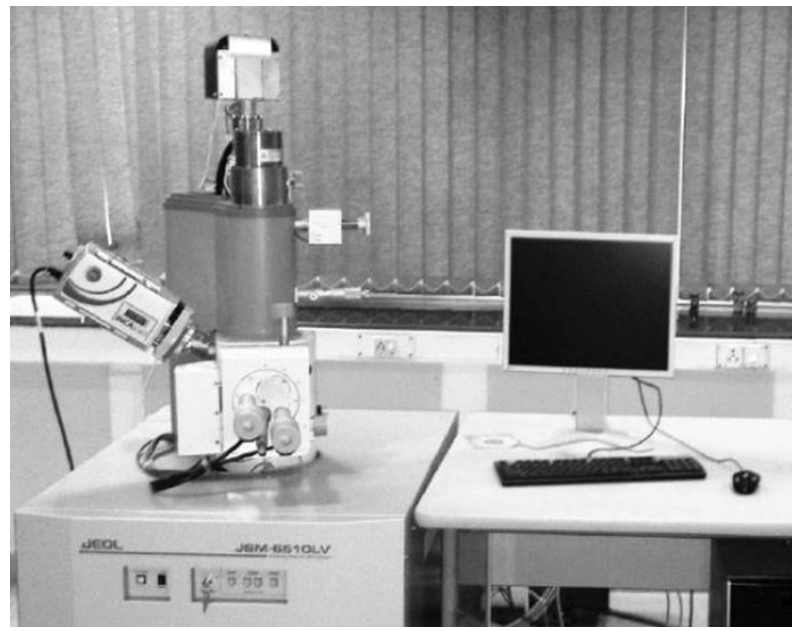

Figure 1. Scanning Electron Microscope used for microstructure analysis (JEOL, Model JSM 6510LV, Japan).
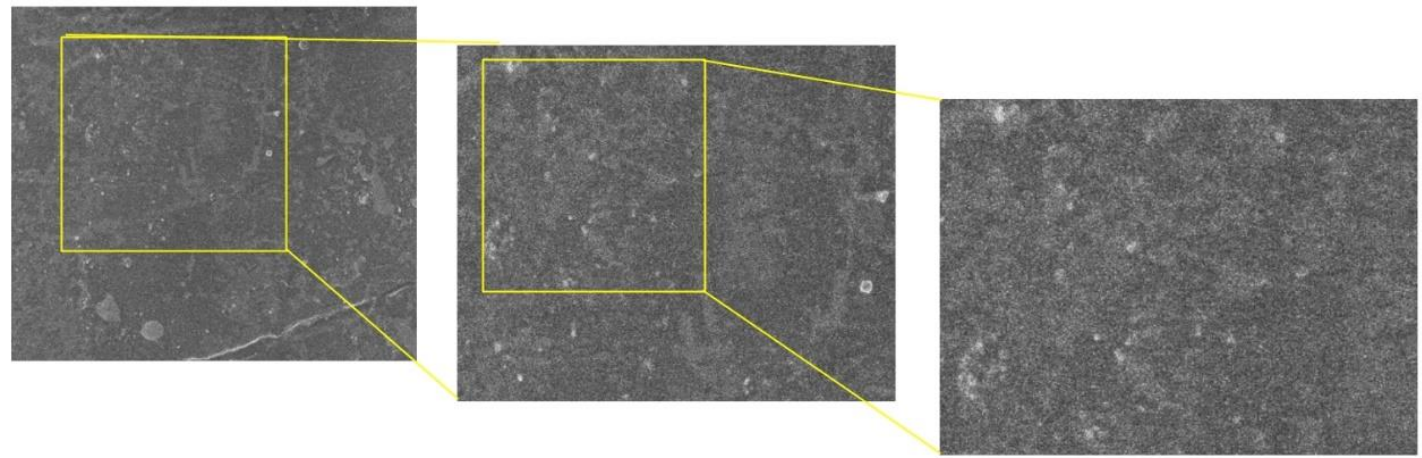

Figure 2. Composite microstructure as viewed from SEM.

\subsection{Fatigue test.}

For any given material, its fatigue life is very crucial as it influences the longevity and reliability of various application components. Fatigue failure of the implant is one of the significant obstructions regarding biomaterials, and the integration of nano reinforcements improves material efficiency, as evidenced in many studies. As depicted in Figure 3, a multiaxial fatigue testing machine (Instron, Model 8801, United States) was used for testing the respective composite specimens, with an aim to analyze the impact of nano composition integration on fatigue properties of a material. Various propositions of nano-graphene oxide were processed for 5 different specimens, for load tensile strength of $60 \%, 70 \%$, and $80 \%$, with uniaxial loading along their length. Figure 4 depicts and compares the S-N curve of each specimen. It is clear from the graph that an increment in the nano reinforcement composition increases the fatigue life of the specimen. However, the curve obtained constantly pushes towards a northeast corner, illustrating a constant increment in the fatigue life which is theoretically not correct because, after a certain period, the accumulation due to nano composition is certain, which would decrease the magnitude of load that the sample could bear before failure. A sample prepared with $0.5 \%$ of graphene oxide demonstrated internal blowholes, which increased with the given time. It is also evident from the S-N Curve (Figure 4) that there is a constant improvement in incrementing the nanoparticles from $0.5 \%$ to $1 \%$ and similarly from $1 \%$ to $1.5 \% \& 2 \%$. However, beyond $2 \%$ there is not a great improvement as visible on increasing from $1.5 \%$ to $2 \%$. 


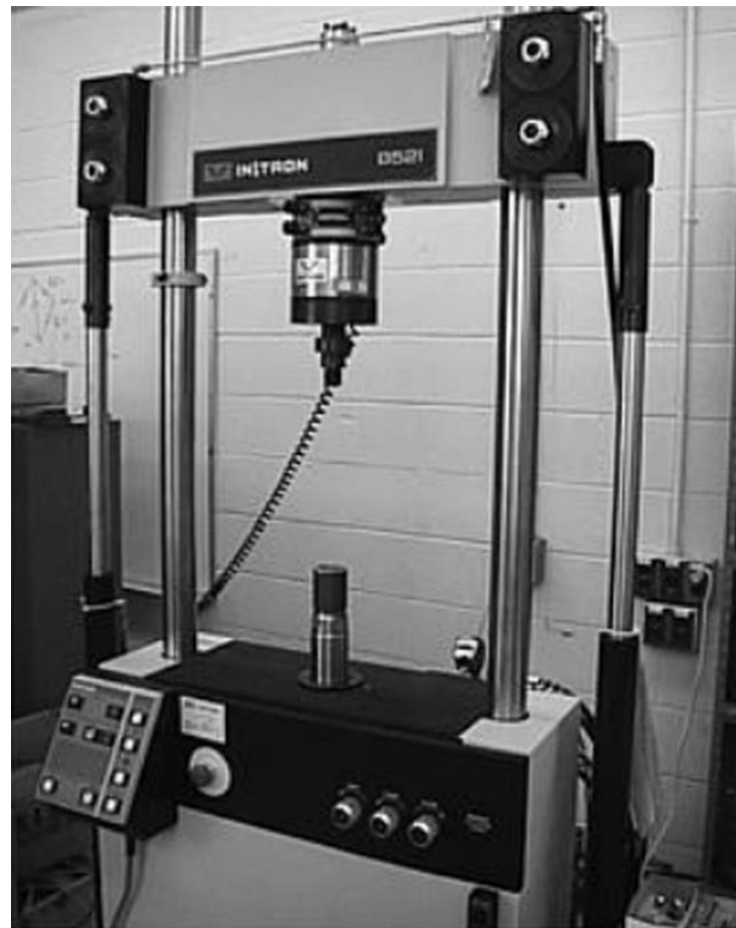

Figure 3. Fatigue Testing Machine (Instron, Model 8801, United States).

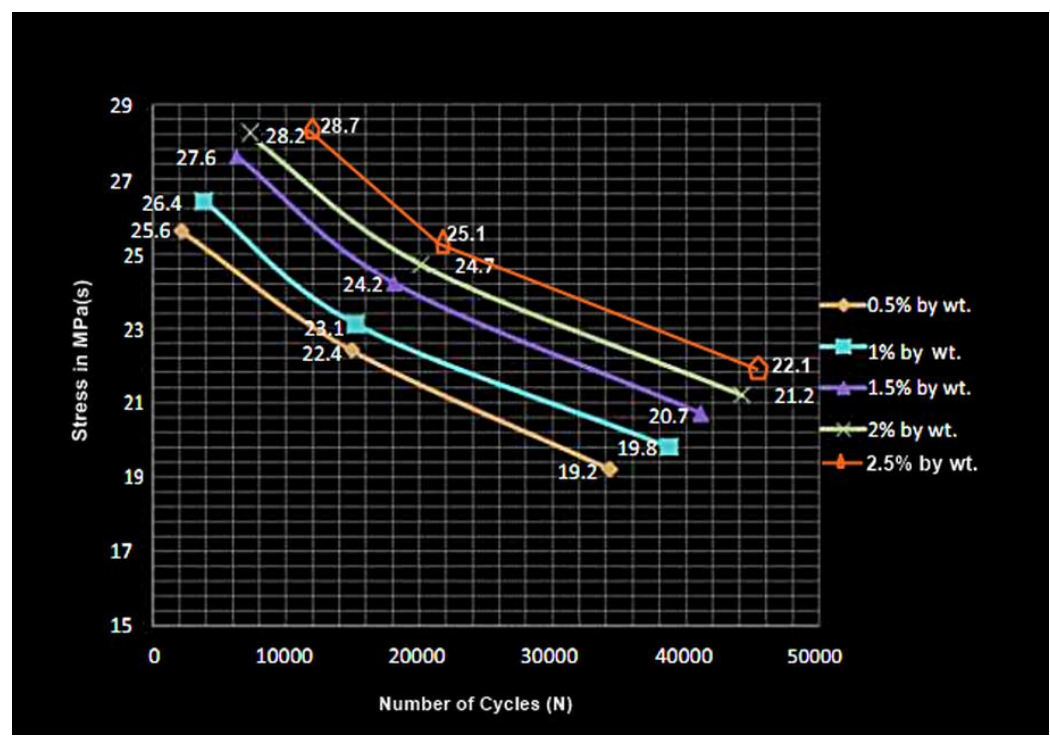

Figure 4. S-N Curve of the different wt.\% of nano-graphene oxide.

\subsection{Wear test.}

The longevity and reliability are two crucial factors that determine the efficiency of a mechanical component. As the component ages, it becomes more prone to wear and tear, which makes the wear test of the proposed composite a requisite, as it should be relevant to the clinical standards. DUCOM pin on the disc was utilized for testing wear characteristics (DUCOM, T25, India), as shown in Figure 5. The experiment for analyzing the wear test of the composite was carried out using an abrasive grinding wheel, connected with a counterweight in order to sustain the wear upon the specimen. 100 RPM for the abrasive disc was set at the beginning of the experimental study. Five composite samples with varying composition, i.e., $0.5 \%, 1 \%, 1.5 \%$, $2 \%$, and $2.5 \%$ of nanoparticles, along with HDPE were selected for analyzing the wear properties, which helps to characterize wear curve because of which the ideal composition 
content can be identified. At a full length of the experiment procedure, the parameters were constant, mainly, the load was fixed at $10 \mathrm{~N}$, along with $100 \mathrm{RPM}$, and wear of 12 minutes was intended. The results obtained from the wear test demonstrated an increment in the wear resistance, along with an increment in the composition of nanoparticles, which can be observed in Figure 6. A sharp decline in the wear trend was observed upon incrementing the weight of reinforcement's concentration from 1.5-2.5 wt.\% shown in Figure 7. A similar result was obtained here as that of fatigue test, where we can clearly see that there is a constant improvement in increasing nanoparticles from $0.5 \%$ to $2 \%$. However, beyond that, the result is not much significant or worthy to be considered. It is clear that the wear properties of composites could be enhanced by incrementing the composition of nanoparticles.

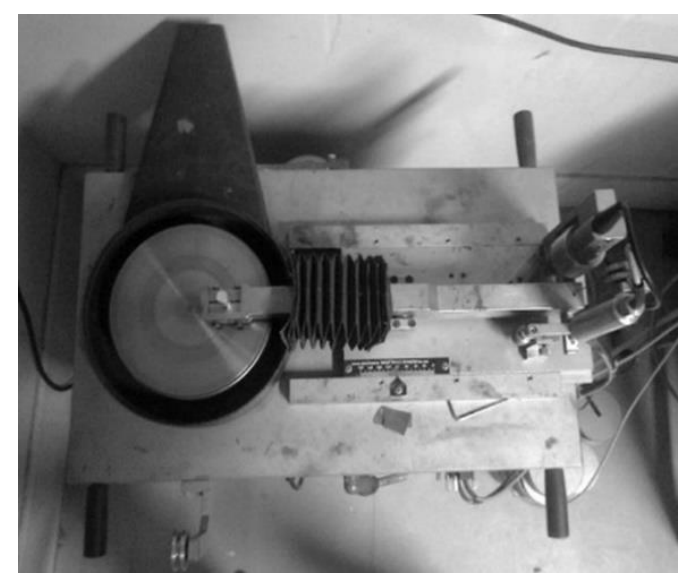

Figure 5. Wear Testing Machine DUCOM, T25, India.

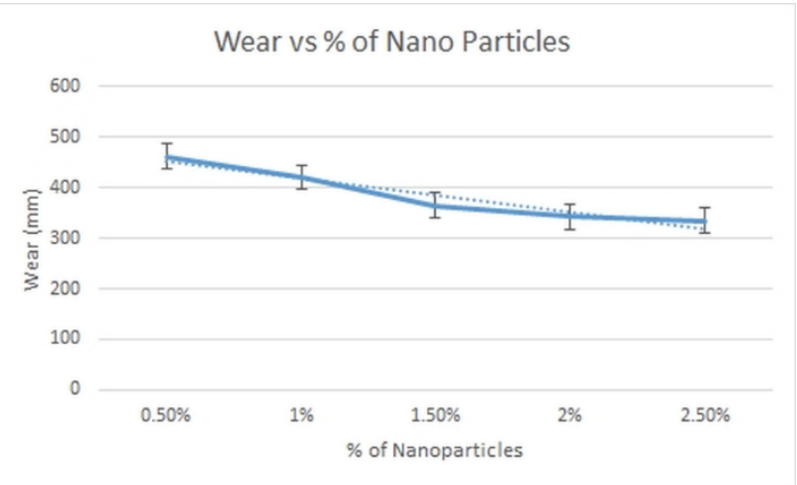

Figure 6. Wear vs. \% of nano-graphene oxide.

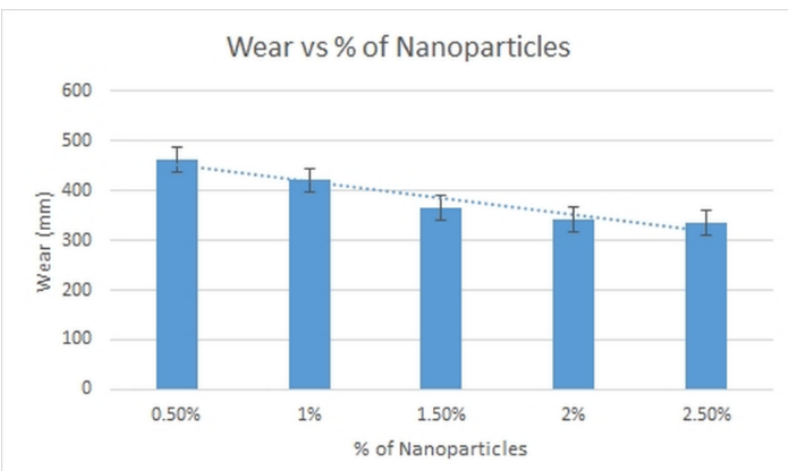

Figure 7. Effect of \% of nano-graphene oxide on wear. 


\section{Conclusions}

HDPE composites upholding a thickness range of $10 \mathrm{~mm}$ were fabricated via a vacuum compression molding technique coupled with water quenching. This method was both effective and efficient for the fabrication of biomaterial of clinical standards. Also, the ultrasonic dispersion method was employed for the distribution of nanoparticles of graphene oxide, done through a melt blending mechanism. The constant temperature throughout the experiment study cannot be maintained during the melting and mixing procedure, which resulted in a colony of blowholes around the partially concave surfaces at the center region of the specimens. Significant improvement in the fatigue $\&$ wear properties of the composite specimen were observed, along with an increment in the tensile strength as well; upon integrating nanographene oxide particles. For specimens having 1.5\%-2\% nanoparticle composition, the distribution of nano-phase reinforcement was ideal, and no accumulation was observed in its microstructure. It can be concluded that $2 \% \mathrm{wt} . \%$ of nanoparticles provides the best results in every testing conditions. The results were not much significant in the difference between the case of $2 \%$ and $2.5 \%$. The polymer matrix and the reinforcement both tend to be biocompatible, but the tests were conducted in regard to the wear and fatigue resistance of the composite, and several other factors also contribute to the final assessment for the proposed composite material. If this composite tends to perform as efficiently upon other biological and mechanical stability parameters, it is safe to remark that it could be considered as an ideal alternative bioimplant.

\section{Funding}

This research received no external funding.

\section{Acknowledgments}

This research received no acknowledgment.

\section{Conflicts of Interest}

The authors declare no conflict of interest.

\section{References}

1. Cui, W.; Bian, Y.; Zeng, H.; Zhang, X.; Zhang, Y.; Weng, X.; Xin, S.; Jin, Z. Structural and Tribological Characteristics of Ultra-Low-Wear Polyethylene as Artificial Joint Materials. J. Mech. Behav. Biomed. Mater. 2020, 104, https://doi.org/10.1016/j.jmbbm.2020.103629.

2. Liu, T.; Huang, K.; Li, L.; Gu, Z.; Liu, X.; Peng, X.; Kuang, T. High Performance High-Density Polyethylene/Hydroxyapatite Nanocomposites for Load-Bearing Bone Substitute: Fabrication, in Vitro and in Vivo Biocompatibility Evaluation. Compos. Sci. Technol. 2019, 175, 100-110, https://doi.org/10.1016/j.compscitech.2019.03.012.

3. Müller, K.; Bugnicourt, E.; Latorre, M.; Jorda, M.; Echegoyen Sanz, Y.; Lagaron, J.; Miesbauer, O.; Bianchin, A.; Hankin, S.; Bölz, U.; Pérez, G.; Jesdinszki, M.; Lindner, M.; Scheuerer, Z.; Castelló, S.; Schmid, M. Review on the Processing and Properties of Polymer Nanocomposites and Nanocoatings and Their Applications in the Packaging, Automotive and Solar Energy Fields. Nanomaterials 2017, 7, https://doi.org/10.3390/nano7040074.

4. Gopanna, A.; Rajan, K.P.; Thomas, S.P.; Chavali, M. Polyethylene and Polypropylene Matrix Composites for Biomedical Applications. In: Materials for Biomedical Engineering. Elsevier, 2019; pp. 175-216, https://doi.org/10.1016/B978-0-12-816874-5.00006-2. 
5. Awad, A.H.; Aly Abd El-Wahab, A.; El-Gamsy, R.; Abdel-latif, M.H. A Study of Some Thermal and Mechanical Properties of HDPE Blend with Marble and Granite Dust. Ain Shams Eng. J. 2019, 10, 353-358, https://doi.org/10.1016/j.asej.2018.08.005.

6. Hsueh, H.C.; Kim, J.H.; Orski, S.; Fairbrother, A.; Jacobs, D.; Perry, L.; Hunston, D.; White, C.; Sung, L. Micro and Macroscopic Mechanical Behaviors of High-Density Polyethylene under UV Irradiation and Temperature. Polym. Degrad. Stab. 2020, 174, https://doi.org/10.1016/j.polymdegradstab.2020.109098.

7. Zhang, Q.; Li, Y.; Cai, H.; Lin, X.; Yi, W.; Zhang, J. Properties Comparison of High-Density Polyethylene Composites Filled with Three Kinds of Shell Fibers. Results Phys. 2019, 12, 1542-1546, https://doi.org/10.1016/j.rinp.2018.09.054.

8. Ramanathan, T.; Abdala, A.A.; Stankovich, S.; Dikin, D.A.; Herrera-Alonso, M.; Piner, R.D.; Adamson, D.H.; Schniepp, H.C.; Chen, X.; Ruoff, R.S.; Nguyen, S.T.; Aksay, I.A.; Prud'Homme, R.K.; Brinson, L.C. Functionalized Graphene Sheets for Polymer Nanocomposites. Nat. Nanotechnol. 2008, 3, 327-331, https://doi.org/10.1038/nnano.2008.96.

9. Harito, C.; Bavykin, D.V.; Yuliarto, B.; Dipojono, H.K.; Walsh, F.C. Polymer Nanocomposites Having a High Filler Content: Synthesis, Structures, Properties, and Applications. Nanoscale 2019, 11, 4653-4682, https://doi.org/10.1039/C9NR00117D.

10. Zhang, F.; Liu, T. Nanodiamonds Reinforced Titanium Matrix Nanocomposites with Network Architecture. Compos. Part B Eng. 2019, 165, 143-154, https://doi.org/10.1016/j.compositesb.2018.11.110.

11. Kundalwal, S.I. Review on Micromechanics of Nano- and Micro-fiber Reinforced Composites. Polym. Compos. 2018, 39, 4243-4274, https://doi.org/10.1002/pc.24569.

12. Li, Y.; Wang, Q.; Wang, S. A Review on Enhancement of Mechanical and Tribological Properties of Polymer Composites Reinforced by Carbon Nanotubes and Graphene Sheet: Molecular Dynamics Simulations. Compos. Part B Eng. 2019, 160, 348-361, https://doi.org/10.1016/j.compositesb.2018.12.026.

13. Faisal, N.; Kumar, K. Mechanical and Tribological Behaviour of Nano Scaled Silicon Carbide Reinforced Aluminium Composites. J. Exp. Nanosci. $\quad$ 2018, https://doi.org/10.1080/17458080.2018.1431846.

14. Emadi, H.; Mobarak, H. Synthesis and Characterization of Copper Ferrite Nanoparticles and Its Application as MRI Contrast Agent. Lett. Appl. NanoBioScience 2019, 8, 541-544, https://doi.org/10.33263/lianbs81.541544.

15. Han, X.; Xu, K.; Taratula, O.; Farsad, K. Applications of Nanoparticles in Biomedical Imaging. Nanoscale 2019, 11, 799-819, https://doi.org/10.1039/C8NR07769J.

16. Sztandera, K.; Gorzkiewicz, M.; Klajnert-Maculewicz, B. Gold Nanoparticles in Cancer Treatment. Mol. Pharm. 2019, 16, 1-23, https://doi.org/10.1021/acs.molpharmaceut.8b00810.

17. Khosravi-Darani, K.; Cruz, A.G. da; Mozafari, M.R.; Abdi, Z.; Ahmadi, N. Biosynthesis of Metal Nanoparticles by Probiotic Bacteria. Lett. Appl. NanoBioScience 2019, 8, 619-626, https://doi.org/10.33263/lianbs83.619626.

18. Naskar, S.; Sharma, S.; Kuotsu, K. Chitosan-Based Nanoparticles: An Overview of Biomedical Applications and Its Preparation. J. Drug Deliv. Sci. Technol. 2019, 49, 66-81, https://doi.org/10.1016/j.jddst.2018.10.022.

19. Burdușel, A.C.; Gherasim, O.; Grumezescu, A.M.; Mogoantă, L.; Ficai, A.; Andronescu, E. Biomedical Applications of Silver Nanoparticles: An Up-to-Date Overview. Nanomaterials 2018, 8, https://doi.org/10.3390/nano8090681.

20. Srinivasan, S.Y.; Paknikar, K.M.; Bodas, D.; Gajbhiye, V. Applications of Cobalt Ferrite Nanoparticles in Biomedical Nanotechnology. Nanomedicine 2018, 13, 1221-1238, https://doi.org/10.2217/nnm-2017-0379.

21. Mathiyalagan, S.; Mandal, B.K. Preparation of Metal Doped Quercetin Nanoparticles, Characterization and Their Stability Study. Lett. Appl. NanoBioScience 2019, 8, 704-710, https://doi.org/10.33263/lianbs84.704710.

22. Harito, C.; Bavykin, D. V.; Yuliarto, B.; Dipojono, H.K.; Walsh, F.C. Polymer Nanocomposites Having a High Filler Content: Synthesis, Structures, Properties, and Applications. Nanoscale 2019, 11, 4653-4682, https://doi.org/10.1039/C9NR00117D.

23. Coleman, J.N.; Khan, U.; Blau, W.J.; Gun'ko, Y.K. Small but Strong: A Review of the Mechanical Properties of Carbon Nanotube-Polymer Composites. Carbon N.Y. 2006, 44, 1624-1652, https://doi.org/10.1016/j.carbon.2006.02.038.

24. Zhao, W.; Li, T.; Li, Y.; O’Brien, D.J.; Terrones, M.; Wei, B.; Suhr, J.; Lucas Lu, X. Mechanical Properties of Nanocomposites Reinforced by Carbon Nanotube Sponges. J. Mater. 2018, 4, 157-164, https://doi.org/10.1016/j.jmat.2018.01.006.

25. Kanagaraj, S.; Varanda, F.R.; Zhil'tsova, T.V.; Oliveira, M.S.A.; Simões, J.A.O. Mechanical Properties of High-Density Polyethylene/Carbon Nanotube Composites. Compos. Sci. Technol. 2007, 67, 3071-3077, https://doi.org/10.1016/j.compscitech.2007.04.024.

26. Murugesan, R.; Gopal, M.; Murali, G. Effect of Cu, Ni Addition on the CNTs Dispersion, Wear and Thermal Expansion Behavior of Al-CNT Composites by Molecular Mixing and Mechanical Alloying. Appl. Surf. Sci. 2019, 495, https://doi.org/10.1016/j.apsusc.2019.143542. 
27. Ma, P.C.; Siddiqui, N.A.; Marom, G.; Kim, J.K. Dispersion and Functionalization of Carbon Nanotubes for Polymer-Based Nanocomposites: A Review. Compos. Part A Appl. Sci. Manuf. 2010, 41, 1345-1367, https://doi.org/10.1016/j.compositesa.2010.07.003.

28. Andrews, R.; Weisenberger, M. . Carbon Nanotube Polymer Composites. Curr. Opin. Solid State Mater. Sci. 2004, 8, 31-37, https://doi.org/10.1016/j.cossms.2003.10.006.

29. Kuila, T.; Bose, S.; Mishra, A.K.; Khanra, P.; Kim, N.H.; Lee, J.H. Chemical Functionalization of Graphene and Its Applications. Prog. Mater. Sci. 2012, 57, 1061-1105, https://doi.org/10.1016/j.pmatsci.2012.03.002.

30. Mittal, G.; Dhand, V.; Rhee, K.Y.; Park, S.J.; Lee, W.R. A Review on Carbon Nanotubes and Graphene as Fillers in Reinforced Polymer Nanocomposites. J. Ind. Eng. Chem. 2015, 21, 11-25, https://doi.org/10.1016/j.jiec.2014.03.022.

31. Park, S.H.; Bandaru, P.R. Improved Mechanical Properties of Carbon Nanotube/Polymer Composites through the Use of Carboxyl-Epoxide Functional Group Linkages. Polymer (Guildf) 2010, 51, 5071-5077, https://doi.org/10.1016/j.polymer.2010.08.063.

32. Kim, H.; Wang, M.; Lee, S.K.; Kang, J.; Nam, J.D.; Ci, L.; Suhr, J. Tensile Properties of Millimeter-Long Multi-Walled Carbon Nanotubes. Sci. Rep. 2017, 7, https://doi.org/10.1038/s41598-017-10279-0.

33. Rahman, G.; Najaf, Z.; Mehmood, A.; Bilal, S.; Shah, A.; Mian, S.; Ali, G. An Overview of the Recent Progress in the Synthesis and Applications of Carbon Nanotubes. C 2019, 5, https://doi.org/10.3390/c5010003.

34. Badakhsh, A.; Lee, Y.M.; Rhee, K.Y.; Park, C.W.; An, K.H.; Kim, B.J. Improvement of Thermal, Electrical and Mechanical Properties of Composites Using a Synergistic Network of Length Controlled-CNTs and $\begin{array}{lllllll}\text { Graphene } & \text { Nanoplatelets. } & \text { Compos. } & \text { Part } & B & \text { Eng. } & \text { 2019, }\end{array}$ https://doi.org/10.1016/j.compositesb.2019.107075.

35. Song, P.; Cao, Z.; Cai, Y.; Zhao, L.; Fang, Z.; Fu, S. Fabrication of Exfoliated Graphene-Based Polypropylene Nanocomposites with Enhanced Mechanical and Thermal Properties. Polymer (Guildf). 2011, 52, 40014010, https://doi.org/10.1016/j.polymer.2011.06.045.

36. Arai, T.; Tominaga, Y.; Asai, S.; Sumita, M. A Study on Correlation between Physical Properties and Interfacial Characteristics in Highly Loaded Graphite-Polymer Composites. J. Polym. Sci. Part B Polym. Phys. 2005, 43, 2568-2577, https://doi.org/10.1002/polb.20543.

37. Kumar, S.; Nehra, M.; Kedia, D.; Dilbaghi, N.; Tankeshwar, K.; Kim, K.H. Nanotechnology-Based Biomaterials for Orthopaedic Applications: Recent Advances and Future Prospects. Mater. Sci. Eng. C 2020, 106, https://doi.org/10.1016/j.msec.2019.110154.

38. Yoon, O.J.; Jung, C.Y.; Sohn, I.Y.; Kim, H.J.; Hong, B.; Jhon, M.S.; Lee, N.E. Nanocomposite Nanofibers of Poly(d, l-Lactic-Co-Glycolic Acid) and Graphene Oxide Nanosheets. Compos. Part A Appl. Sci. Manuf. 2011, 42, 1978-1984, https://doi.org/10.1016/j.compositesa.2011.08.023.

39. Ghodrati, H.; Ghomashchi, R. Effect of Graphene Dispersion and Interfacial Bonding on the Mechanical Properties of Metal Matrix Composites: An Overview. FlatChem 2019, 16, https://doi.org/10.1016/j.flatc.2019.100113.

40. Jin, X.; Wang, J.; Dai, L.; Wang, W.; Wu, H. Largely Enhanced Thermal Conductive, Dielectric, Mechanical and Anti-Dripping Performance in Polycarbonate/Boron Nitride Composites with Graphene Nanoplatelet and Carbon Nanotube. Compos. Sci. Technol. 2019, 184, https://doi.org/10.1016/j.compscitech.2019.107862.

41. Jiang, X.; Drzal, L.T. Properties of Injection Molded High Density Polyethylene Nanocomposites Filled with Exfoliated Graphene Nanoplatelets. In: Some Critical Issues for Injection Molding. 2012, https://doi.org/10.5772/35328.

42. Wei, X.; Meng, Z.; Ruiz, L.; Xia, W.; Lee, C.; Kysar, J.W.; Hone, J.C.; Keten, S.; Espinosa, H.D. Recoverable Slippage Mechanism in Multilayer Graphene Leads to Repeatable Energy Dissipation. ACS Nano 2016, 10, 1820-1828, https://doi.org/10.1021/acsnano.5b04939.

43. Wang, Y.; Mei, Y.; Huang, F.; Yang, X.; Li, Y.; Li, J.; Meng, F.; Zhou, Z. Ultra-Robust and High-Toughness Graphene Oxide Papers via Synergistic Strengthening by Addition of Carbon-Nanotubes and Copper Ions. Carbon N. Y. 2019, 147, 490-500, https://doi.org/10.1016/j.carbon.2019.03.009.

44. Chanfrau, J.E.R.; Pantoja, Y.V.; Guastaldi, A.C. Ultrasonic Application and Spray Drying during Amorphous Calcium Phosphate Synthesis. Lett. Appl. NanoBioScience 2019, 8, 711-714, https://doi.org/10.33263/lianbs84.711714.

45. Kumar, S.; Wu, C.S.; Padhy, G.K.; Ding, W. Application of Ultrasonic Vibrations in Welding and Metal Processing: A Status Review. J. Manuf. Process. 2017, 26, 295-322, https://doi.org/10.1016/j.jmapro.2017.02.027.

46. Mousavi, S.A.A.A.; Feizi, H.; Madoliat, R. Investigations on the Effects of Ultrasonic Vibrations in the Extrusion Process. J. Mater. Process. Technol. 2007, 187-188, 657-661, https://doi.org/10.1016/j.jmatprotec.2006.11.168.

47. Muley, S.V.; Singh, S.P.; Sinha, P.; Bhingole, P.P.; Chaudhari, G.P. Microstructural Evolution in Ultrasonically Processed in Situ AZ91 Matrix Composites and Their Mechanical and Wear Behavior. Mater. Des. 2014, 53, 475-481, https://doi.org/10.1016/j.matdes.2013.07.056. 
48. Srivastava, N.; Chaudhari, G.P. Microstructural Evolution and Mechanical Behavior of Ultrasonically Synthesized Al6061-Nano Alumina Composites. Mater. Sci. Eng. A 2018, 724, 199-207, https://doi.org/10.1016/j.msea.2018.03.092.

49. Kim, H.; Kobayashi, S.; AbdurRahim, M.A.; Zhang, M.J.; Khusainova, A.; Hillmyer, M.A.; Abdala, A.A.; Macosko, C.W. Graphene/Polyethylene Nanocomposites: Effect of Polyethylene Functionalization and Blending Methods. Polymer (Guildf). 2011, 52, 1837-1846, https://doi.org/10.1016/j.polymer.2011.02.017.

50. Anderson, K.S.; Lim, S.H.; Hillmyer, M.A. Toughening of Polylactide by Melt Blending with Linear LowDensity Polyethylene. J. Appl. Polym. Sci. 2003, 89, 3757-3768, https://doi.org/10.1002/app.12462.

51. Li, Y.; Shimizu, H. Toughening of Polylactide by Melt Blending with a Biodegradable Poly(Ether)Urethane Elastomer. Macromol. Biosci. 2007, 7, 921-928, https://doi.org/10.1002/mabi.200700027.

52. Ponnamma, D.; Cabibihan, J.J.; Rajan, M.; Pethaiah, S.S.; Deshmukh, K.; Gogoi, J.P.; Pasha, S.K.K.; Ahamed, M.B.; Krishnegowda, J.; Chandrashekar, B.N.; Polu, A.R.; Cheng, C. Synthesis, Optimization and Applications of ZnO/Polymer Nanocomposites. Mater. Sci. Eng. C 2019, 98, 1210-1240, https://doi.org/10.1016/j.msec.2019.01.081.

53. Ahmad, H.; Fan, M.; Hui, D. Graphene Oxide Incorporated Functional Materials: A Review. Compos. Part B Eng. 2018, 145, 270-280, https://doi.org/10.1016/j.compositesb.2018.02.006.

54. Puértolas, J.A.; Castro, M.; Morris, J.A.; Ríos, R.; Ansón-Casaos, A. Tribological and Mechanical Properties of Graphene Nanoplatelet/PEEK Composites. Carbon N. Y. 2019, 141, 107-122, https://doi.org/10.1016/j.carbon.2018.09.036 